\title{
Portrait of the 'absent' father: the impact of non-residency on developing and maintaining a fathering role
}

\author{
MARY P. CORCORAN \\ Department of Sociology, NUI Maynooth
}

\begin{abstract}
This paper reports on an exploratory study conducted with nonresident fathers, to elucidate the key issues affecting the development and maintenance of a fathering role after a relationship has ended. In particular, the paper focuses on the contingent nature of fatherhood for young marginalised men in Dublin. The extent to which fathers identify with a fathering role is explored and comparisons are drawn between the experiences of estranged, committed and activist fathers. Key factors that militate against fathers maintaining an active role in their children's lives are identified. The paper concludes that while the experiences of fatherhood vary across different categories of fathers, the majority of them aspire toward and value their fathering role. However, their capacity to adopt a positive fathering role is affected by a range of institutional, economic and social barriers.
\end{abstract}

\section{Background}

The National Economic and Social Forum (NESF) convened a project team to examine issues relating to lone parents in 2000. In the course of the project team's work, the terms of reference were expanded to include a focus on the issue of fatherhood, or more specifically, those fathers who do not live with the mothers of their children. A qualitative study was undertaken in order to find out more about the experiences of non-resident fathers. ${ }^{1}$ The report on Lone Parents by NESF issued in July 2001, and contained a discussion of non-resident fathers in the context of family formation issues and the changing profile of Irish families (NESF, Forum Report No. 20, 2001). This article re-visits the data collected from non-resident fathers in the spring of 2001 in order to elucidate some of the key issues faced by such fathers in contemporary Irish society. 


\section{Non-resident fatherhood}

Not only is fatherhood 'central to men's identities', but 'the changes associated with fatherhood are pervasive and profound' (Palkovitz et al., 2001: 55). Yet the implications for fatherhood and the fathering role have until recently received little sustained attention in the literature on lone parenthood and family breakdown. Men as fathers may be wholly absent from the lives of their children, intermittently present through informal access arrangements or wholly present through joint custody arrangements or other formal access rights. Alternately, they may occupy the status of lone parent with full responsibility for the rearing of their children. In the academic, political and policy discussion about lone parenthood very little attention has been paid to the concerns and experiences of men in relation to out of marriage conceptions and out of marriage child rearing. However, in recent years, the psychological and sociological factors that affect lone fathers are increasingly acknowledged in relation to lone parenthood:

A restructured labour market, debates about equal opportunity, changes in family formation, have all forced a rethink about fathers, both as individuals and as a resource within families (Speak, Cameron and Gilroy, 1997: 16).

A number of factors have militated against the father's experience being recognised in studies and reviews of lone parenthood. Lone fathers are not at such a significant risk of falling into poverty as lone mothers so they are not strictly speaking within the target 'at risk' group. Furthermore, fathers do not constitute as visible a group as mothers in the familial, community and neighbourhood contexts. Young mothers are more likely to be involved in formal and informal community networks. There are many more services directed at them, and for that reason, they are frequently more accessible for the purpose of carrying out research. The association of parenting with mothering rather than fathering means that most support services for families tend to avoid fathers (McKeown, Ferguson and Rooney, 1998). Traditional role assignations within families have proved remarkable resilient. Women are still the primary caregivers and there is little evidence to show the willingness of fathers to share care-giving tasks with women, (Kiely, 1998: 94). Indeed, the increased participation of mothers in the labour force has not brought about a corresponding participation of men in household tasks and childcare within the family. Rather, the expansion of women's roles and the general democratisation of family life means that fathers increasingly lack a template for how fathering should be performed (Kiely, 1995: 155). Clearly, the role confusion around fathering can only be exacerbated for those men who find themselves estranged from their former partner or spouse and the children.

The focus of studies on lone parents has largely concentrated on the motherchild dyad, not just in Ireland but internationally. Fathers in so far as they feature do so only in relation the thorny issues of maintenance payments and custody 
arrangements. Fathers by and large have remained shadowy figures on the margins of political and policy debate. In the Irish context, Kiely notes that very little research has been carried out to evaluate the significance of structural obstacles to fathers maintaining contact with their children following separation (2000: 583). In her study of a small sample of previously married men parenting alone, Quill identified a number of key challenges including the aftermath of dealing with marital breakdown, difficulties in getting custody of children, psychological effects of lone fatherhood and the pressure of adopting the dual roles of 'breadwinner' and 'homemaker' (2000: 78-81). Some fathers in Ireland are parenting alone and while they share many of the same concerns as mothers parenting alone, they also report particular difficulties in relation to how they are viewed by service providers, by their own families and by neighbours. They may feel marginalised because of their exclusion from the familial and social networks that provide a lifeline for many lone mothers (Russell and Corcoran, 2000: 29).

A second category of fathers that has received little attention to date, are the 'absent' fathers of unmarried lone parents. While it is important to acknowledge that unmarried fathers are not debarred from parental responsibility or the legal status of fatherhood, their parental rights in law fall short of those held by married fathers and they are not acquired automatically (Burghes, Clare and Cronin, 1997: 2). While efforts have been made to safeguard the rights of lone parents and their children, little attention has focused on the rights and interests of the fathers of those children. When children and fathers live apart (and under the co-habitation rule this is a condition of eligibility for the One-parent Family Payment ${ }^{2}$ ) contact between them is almost always reduced and this is likely to increase over time, (Burghes, Clarke and Cronin, 1997: 3). The existing research suggests that there is a multiplicity of factors that may influence, or are associated with the quantity of contact which a non-resident father has with his children. Some of these associations appear to have been established more conclusively than others (e.g. time since separation, geographical distance). Contact levels also vary by marital status. Ex-married fathers are much more likely to see their children regularly, than either ex co-habiting fathers, or fathers who were non-resident (Bradshaw et al., 1999: 83). It must be noted, however, that low levels of contact between non-resident fathers and their children does not necessarily reflect a lack of interest on the part of fathers. Rather, it is equally plausible that personal, social, legal and financial barriers militate against their assumption of a more involved fatherly role.

Research undertaken in the United Kingdom which explored the experiences of a small sample of young single non-residential fathers who had managed to maintain contact with their children, found that young fathers were concerned about being there for their children, and that their children knew who they were. Most of these fathers found that access to their child was controlled not only by the mother of the child but also by the mother's family and any new partner. The study concludes that there should be an acceptance of the rights of the child to know, and if possible, be supported by both its parents (Speak, Cameron and Gilroy, 
1997). Bond goes further arguing in favour of a system of representation for children that would safeguard their right to form a meaningful relationship with both of their parents. Specifically, she suggests that there should be 'separate representation for children and extended independent child-centred support should be available, as a matter of course, to separating families' (1998: 13).

The absence of support structures for non-resident fathers in the aftermath of relationship breakdown is an ongoing political issue. Several high profile campaigns, notably in the United Kingdom, ${ }^{3}$ have attempted to highlight perceived inequities in the law and welfare policy that, it is claimed, negatively impact on fathers' relationships with their children.

\section{Methodology}

The objective of the qualitative research study was to identify a cross-section of non-resident fathers including those who had never married as well as those who were separated and divorced, and ascertain their views and experiences of fathering. To this end seven focus groups were convened. Due to pressure of time, and the difficulties in getting the groups set up, all the focus group discussions were confined to the Dublin area. ${ }^{4}$ The participants were accessed through a variety of sources. As a first line of inquiry I contacted people involved in youth/ community work who were likely to have a brief in relation to the provision of services to young people including men. These first order contacts gave rise to second order contacts with whom I negotiated in order to convene the required groups. Additionally, I contacted existing lobby groups who represent the interests of non-resident fathers. Some agencies/services also made known their willingness to the NESF secretariat to engage in a discussion group. In addition to the focus groups, interviews were conducted with staff at a Men's Centre, and at a Men's Network/Family Resource Centre in North Dublin. Telephone interviews were also conducted with a number of other service providers in the field of youth services. In all, the views and experiences of more than forty men were recorded and analysed. Those who participated ranged from eighteen years of age to late fifties, and were from a variety of social class backgrounds. The young fathers who participated in two focus groups, however, were all from a disadvantaged background.

The focus groups covered a number of themes including the circumstances of becoming a father, the extend to which men identified with a fathering role and how that changed in the post-marital or post-relationship situation, factors that helped or hindered fathers' acknowledgement, access and continued relationship with the mother and child and more generally how fathers, and in particular, nonresident fathers view themselves in Irish society. The research conducted was limited in scope, and the views presented here cannot be seen as representative of those of all non-resident fathers in Ireland. Nevertheless, the findings from the focus groups do provide considerable insight into the impact of non-residency on developing and maintaining a fathering role in the Irish context. ${ }^{5}$ Given the fact 
that marriage dissolution is on the increase, and that the proportion of births to lone parents remains at a historical high, a strong case can be made for doing more systematic, longitudinal research to ascertain the key issues of concern to nonresident fathers in contemporary Irish society.

\section{Becoming a non-resident father}

There are many routes into non-resident fatherhood (see McKeown, 2000) and all of these were reflected in the narratives of the respondents in the focus groups. The most common routes were as follows: (1) The break-up of a marriage in which the father moves out of the family home and is subsequently granted through court order or informal agreement limited access to his children; (2) The break-up of a long-term relationship (in excess of one year) after the child was born leading to a prolonged struggle to maintain contact and secure access/visitation rights; (3) The break-up of a short-term relationship (less than one year) after the child was born leading to a continuous struggle to maintain contact and secure access/visitation rights; and (4) The birth of a child after a casual encounter leading to attempts to establish paternity and a relationship with the child. These different experiences were closely linked to the age of the respondents. Marriage and longterm relationships were much more common among the older participants (ranging in age from their late twenties through to their fifties) who had frequently planned for and actively chosen fatherhood. In contrast, younger fathers (ranging in age from late teens to early twenties) from a disadvantaged background were likely to have entered fatherhood as a result of a casual encounter or a non-committed relationship. In other words, entering fatherhood was a contingent event that was totally unplanned for. It is this route into fatherhood that I will explore here.

\section{Fatherhood as a contingent event}

For the younger fathers uncertainty, ignorance and a lack of knowledge were barriers to their understanding of and participation in the new situation as the following testimonies demonstrate:

'She told me she was four months gone, then she was premature so she went into labour at six months so it wasn't even sinking in. It was just starting to sink in and then she was in the hospital and I was told I was going to be a Da in the next couple of hours. I didn't know what to think at all because I really didn't know what was going on.' (Young father, North Dublin)

'His parents got married because his mother was pregnant. And his Ma's was only 17 , and his Da was only 18 . And they offered him no support. He hadn't a clue. And it wasn't like ...well nobody has a clue with a new baby. You just have to learn as you go along. But the emotional side of it. He hadn't got a clue how to deal with it-being a Da like. I had Cherish. I had the 
support of other single mothers. And I had me sister. I had me Ma. But he had no one to talk to at all.' (Young mother, Youthreach programme)

In some cases the issue of taking on a new parenting role was complicated by the problem of establishing paternity. Among the young men from the North Dublin suburb there appeared to be a high degree of sexual promiscuity characterised by transient relationships, one-night stands, and several men going out with the same girl at once. On the subject of taking responsibility for sexual activity most of the young men felt that taking precautions was a matter for the young woman. These traditional attitudes toward sexuality are far more entrenched in society than we sometimes allow for. For example, an investigation into the sex lives of teenagers in Britain over a ten-year period found that while the taboo about premarital sex had been broken, the traditional idea that sex is a man's pleasure and a woman's duty is alive and well (Holland et al., 1998). Young girls who took responsibility for their sexuality by carrying condoms or asking for their use signalled a lack of innocence and thus, ran the risk of being labelled as 'slags.' In a similar vein, a U.S. study of the sexual activity of adolescent males found that one-third of those sampled believed that preventing a pregnancy was a woman's job (Huang and Han, 2004: 745). A recently published study commissioned by the Crisis Pregnancy Agency also found evidence that there is still a strong discourse about women having sex outside of relationships being labelled in a certain way (Murphy-Lawless, 2004). The young fathers from North Dublin expressed their dislike of condoms and suggested that most sexual encounters were spontaneous, unplanned for, and frequently occurred when both parties were under the influence of alcohol:

'I'm nineteen and it would have been about three years ago, three Christmas's ago me young one told me she was pregnant by me. But I was with her for a few months and it was finished for a few months and I got back with her for a week and then she told me like 'I'm pregnant'. So I said, 'listen, I was only with you for a week so what's the story?' and she said 'no it's from the last time. So I said 'you were with a load of people since when we spilt up so it went on and on. A lot of young ones are coming over and they think I am a scumbag for not owning up and that. So I promised I'd pay for a blood test when the kid was born. Me mate went through it and it was bad with him so I wasn't going through anything like that'. (young father, North Dublin)

'It's like a soap opera. There is a gang of young ones, down and out sluts. They get really drunk and do four or five blokes in a week. More young ones than young fellas you see, that's how sexual diseases get passed.' (young father, North Dublin)

This attitude toward sexuality is not necessarily out of synch with that of Irish society as a whole. In fact, young men from a disadvantaged background may be 
expressing a sexual attitude that is simply at the more extreme end of an attitudinal continuum in which drinking and having unprotected sex are closely linked. A second study recently published by the Crisis Pregnancy agency has indicated that non-use of contraception was generally associated with older age, lower educational level, lower social class and casual relationship status (Rundle et al., 2004). Forty-five per cent of men in the national sample admitted that drinking alcohol had contributed to having sex without contraception.

Casual sexual encounters that result in pregnancy lead to very fluid household arrangements. As McKeown (2000) points out, households and families are not coterminous. For example, after a child is born the young father may move into the mother's family home to help out for the first few months. He may later return to his own family of origin, while maintaining relations with his child. (There were also cases where the opposite happened and the young woman moved into the home of the paternal grandparents). Subsequently, the father or mother may have another child with another partner complicating matters further.

An additional factor that militates against young men taking up a fathering role, is the effect of the cohabitation rule. The welfare regime currently requires that a person in receipt of one-parent Family Payment may not cohabit, and if he or she does so, will lose their welfare entitlement. In cases where cohabitation occurs the residency of the father is often denied and evidence of his presence in the home is hidden. This leads to a distortion of the relationship between the father and mother, and the father and his children. A men's advocate in North Dublin, suggested that while more that 40 per cent of households in his neighbourhood were headed by lone parents, in actual fact, up to 80 per cent of those households were comprised of cohabiting couples. He argued that the prohibition on cohabitation for those in receipt of social welfare payments leads to the erosion of the family and the marginalisation of men:

'When children answer the door they are conditioned to deny that their father lives there, and efforts are made to keep evidence of the father hidden. We should offer these people an amnesty and encourage them into the labour market through the Back to work scheme and allowances.' (Men's advocate, North Dublin)

This suggestion that welfare policy should be reconfigured toward helping informal family units to help themselves, was echoed recently by O'Toole who argues that all lone parents should be guaranteed their welfare benefits until their children reach eighteen years, regardless of what living arrangements they organise for themselves. This would have the effect of removing 'the perverse disincentive that stops a quarter of all lone parents establishing long-term relationships' (2004: 16). It may also make it somewhat easier for disadvantaged young men, in particular, to maintain ongoing commitments both to their partner and their child, thus strengthening their fathering role. 
It is to the issue of identification with the fathering role that we now turn. The men consulted in the focus groups broadly fell into one of three categories: the estranged father, the committed father and the activist father. I shall deal with each of these in turn.

\section{Estranged fathers}

Estranged fathers had lost contact with their children for a variety of reasons. For example, one man had fathered a child 15 years ago, but lost contact when the mother walked out of his life moving to another part of Ireland. Despite repeated attempts to contact the mother of his child he had been rebuffed. He carried a photograph of his daughter in his wallet (when she was aged four years old, the last time he saw her). He says he thinks about her every day and is determined to reestablish contact but is unsure of how he should do this or to whom to turn for help. Another man, now 27 years fathered a child seven years ago. Although he had acknowledged the child, his current partner and the mother of his other child will not permit him to have contact with his seven-year old son:

'I went up to see him at Christmas with presents and stuff and he kissed me on the cheek and kept calling me Daddy and all. But my bird- she called me a scumbag for going up to see "that bastard".' (Father, North Dublin)

In both cases presented here, the men were relatively immature when they embarked on parenthood. The end of the relationship meant the end of meaningful contact with the child. In the former case, success at overcoming a long-term drug abuse problem had reawakened latent feelings and emotions about a 'lost' child. This respondent, who has children with his current partner, feels acutely the loss of a father-daughter relationship with his first child and yearns to be re-united with her. In the latter case, the child in question resulted from a casual sexual encounter. The young man has moved on and is under considerable pressure from his current partner 'to lose' the past, as she feels threatened that his loyalties may lie elsewhere.

He neither has the emotional nor financial resources to provide a positive role model for his child, although he does express feelings of love toward him.

Estranged fathers crossed the age spectrum from those in their late teens to those in the mid-forties. They expressed feelings of sadness and in some cases bitterness about being cut off from their children. ${ }^{6}$

\section{Committed fathers}

Committed fathers were in contact with their children to varying degrees. Some young men had informally worked out shared parenting arrangements with the mothers of their children, even when the relationship itself was over. Others saw their fatherhood in terms of helping out with a night of 'babysitting' here or a 'day 
in town there', and seemed content with occupying an occasional presence in their child's life. All of those who fell into this category had a positive self-identification as fathers and were committed to playing a role in their children's life, even if in some cases, that role was relatively marginal:

'Sometimes on a Sunday I'd baby-sit from 1 o'clock to 7 o'clock because she has to go to work, and on a Saturday I'd probably baby-sit for a few hours for her. I would just play with him in the house and bring him out for walks ' $n$ all. He's motorbike mad and if he sees a bike its just 'bike, bike, bike' so I have me mope head and I might bring him around the garden on it. That makes his day and he gets such a buzz out of it. He's smiling for the rest of the day.' (Young father, North Dublin)

One young mother on the Youthreach programme could not praise the father of her friend's child enough, although considerably uncertainty hung over his future because of an outstanding serious assault charge against him:

'He hasn't got millions of charges against him, sure he doesn't? Am I right in saying that? He's nice ... he was on our course. I know him as well. He's a lovely fellow and he's a great Daddy. He's great to [...] isn't he? Anyone who knows him, he's great and he's always there. And he's a good father in my opinion anyway.' (Young mother, Youthreach programme)

Other researchers have also reported that fathers from disadvantaged backgrounds do care about their children and that many are making irregular informal contributions (Furstenberg et al., 1992, Edin and Lein, 1997). Furthermore, researchers have found that poor mothers and fathers have defined the role of fatherhood to emphasise emotional support and guidance over economic responsibility. However, the young fathers in this study frequently lacked the capacity to provide the emotional support necessary to the mother of their child. Several younger fathersthat is, fathers in their late teens or early twenties, reported feelings of alienation in relation to the mothers of their children, a finding borne out by a British study which found that young men were ill equipped to deal with relationship issues that develop as a result of fathering a child (The Prince's Trust, 2001: 35). Respondents felt that their girlfriends/former girlfriends had changed after the birth of the child and they had great difficulty communicating with them. They attributed this to the hormonal changes that they felt must occur after birth and which they had observed in sisters and with other friends' girlfriends. All felt that pregnancy and childbirth had changed their girlfriends/ex-partners and that this had put excessive pressure on the relationship. They felt they had to tiptoe around the young women, that arguments would start over the smallest thing, and that the only way to survive the storm was to keep their mouths shut and try to defuse the situation at all costs: 
'For the last few months like you'd be talking to her grand one minute and then next she'd just have these dirty mood swings and you'd be on the end of it getting a roasting for stupid things. You'd think everything was grand and then you might just change the channel on the television or something and she'd just go right of the wall and she'd start bringing up things...stupid things just to have an argument with you. She's a bit mad like that.' (Young father, North Dublin)

In almost all cases, the mother of the child was perceived to have all the control in the relationship a fact that created feelings of anger and fear as well as undermining the role of the father in his attempts to co-parent.

In general, committed fathers saw their parenting role as a supplement or support to the primary role of the mother, and the mother's family. While acknowledging the changed situation, and the fact that they had to make certain adjustments, they did not see the fathering role as fundamentally altering the structure of their daily lives. However, they were of the opinion that having a girlfriend and a child had 'quietened them down.' A new sense of responsibility had ensued, and they now had to evaluate their lives and adapt themselves to the new circumstances. Research bears out the positive impact of contact between a non-resident father and his children. A British study which focused on the lives and experiences of disadvantaged young people found that 'young fathers who were playing an active role in bringing up their children had in some cases gained a sense of purpose and stability, but those who were not involved were dealing with painful emotions such as guilt, hatred or a sense of failure' (The Prince's Trust, 2001: 34).

\section{Activist fathers}

In contrast to the first two groups, activist fathers are primarily comprised of those who had formerly been married, who had shared a home and the upbringing of their children before marital or relationship breakdown. A significant difference between activist fathers and committed fathers is that the former tend to be older, that is, to be aged from the late twenties into the fifties. They have also had more direct and ongoing experience of the fathering role. While younger fathers had often entered fatherhood in a spontaneous and contingent manner, activist fathers had generally planned for, and actively participated in the rearing of their children. They experienced deep hurt and trauma in the aftermath of marital breakdown. They perceived the judicial system to be biased very much in favour of women and hence perceived themselves as embattled, as they struggled through the courts to gain more access rights to their children:

'I was in court thirty-four times. She was granted sole custody, and I went in looking for joint custody and shared parenting. The High Court eventually over turned that ruling and after four years in and out of court I established 
my right to joint parenting. That was the day things started to change. Then she [ex-wife] started to work with me and put a plan in place and we've never looked back since then.' (Member of a fathers' advocacy group)

Older fathers readily identified with the father role primarily seeing themselves as co-parents in their children's lives, even if access to the children was limited. All the fathers were strongly of the view that children need two parents, and that at particular stages in the lifecycle- during boys' teenage years for example- the presence of a father figure is crucial. Interestingly, younger fathers whose children were being raised by the mother in her mother's home, strongly felt that they could provide a masculine role model, especially for sons, growing up in largely female environment.

In the focus group discussions many of the fathers who had adapted an activist strategy toward their fathering role, expressed ambivalence about their former wives/partners. On the one hand, they recognised that the children had been conceived in love, longed for and cared for together in the early years of marriage or the relationship. The end of the marriage brought with it the reality that the family was reconfigured around the mother and the family home, with the father being allotted the role of 'visitor in his child's life'. This created considerable tension and bitterness for these fathers:

'I mean the situation was as I saw that I was a very concerned parent from day one. My wife and I had plans, like our future, there were children in the future and we'd spoken about it and we were living with each other and she was very career oriented and so was I. We had two successful jobs. As time went on I was doing more and more with the children and she was doing less and less. I was constantly refocusing my career to take the children's needs into consideration as I saw it. Matters came to a head. And she left and from a position where I was the primary care giver for my children the equation flipped in something like a day. She walked out with the children and they became the currency in the relationship.' (Separated father, fathers' support group)

All the fathers expressed feelings of love for their children and strongly argued that they had much to offer their children apart from financial support. Those who had lost contact or had had access to their children reduced likened their situation to bereavement that is not acknowledged, and has no finality for them.

\section{Factors that impact on the father's continued relationship with his child}

The key mechanisms through which contact was maintained between fathers and their children were the payment of maintenance and the rights of access. These mechanisms were inextricably bound together in the eyes of most fathers, 
particularly if they have been through the court system. The adversarial nature of the Irish court system and the in camera rule $^{1}$ in the family courts were widely condemned by those fathers who have had experience of the system. They strongly believed that the courts do not take the role of fathering seriously and that this impacts on decisions in relation to access and joint parenting. Mediation services which were viewed by several fathers as 'window dressing', were not seen to offer a serious alternative to the legal system. This may be because in an acrimonious marital breakdown situation, the parties are unable to re-establish the kind of mutual trust necessary for successful mediation. The fathers see the legal system as binding, and therefore, as offering the best hope of legitimating their rights of access to their children.

Even for younger fathers who had worked out only informal arrangements with the mothers of their children, a clear connection was made between the payment of money and a reciprocal right to see the child. Responsibility is defined largely in monetary terms. It follows that if a young man was not able to pay the money, or annoyed the young woman in some other way, access to the child could be immediately withdrawn. Fathers felt particularly strongly about the imbalance they saw in charging fathers with responsibility without also conferring reciprocal custodial rights. That is, they believed that the payment of maintenance indicated their commitment to their children and that accordingly they should be granted more generous access to those children. But frequently, access to the child was used as a bargaining device. All fathers condemned the use of the child as a 'tool', a 'weapon', a 'pawn', or as 'currency' in the aftermath of marital or relationship breakdown.

Relationships between non-resident fathers and children were seriously affected by what they perceived as the shortcomings of the access system. When access hours are delineated by the court they tend to be relatively restrictive. This leads to fathers spending short periods of time in intensive interaction with their children. The compression of the relationship into short periods of time affected the bond that evolved between child and parent:

'The thing is the dynamic that happens with the child. If you have a child for only a few hours it is highly intensive. Whereas it would be more healthier if you had long spaces of time when you can settle down, even in separate rooms and they can wander in and out if they have something to say to you. It is a totally different relationship than being a visitor in your child's life bringing them to McDonalds and buying them presents.' (Separated father, fathers' advocacy group)

'I found that with my children. ... I used to do a lot of cooking with my daughter, making instant bread ... and I found it was only in the last half hour of the access that you were getting to know them. And then, jump, Jesus lads, get the coats back on, out in the cold, must go, just in case the first bus doesn't come.' (Separated father, fathers' advocacy group) 
A recently reported Australian study suggests that children who had frequent contact (at least monthly) were twice as likely as those with infrequent contact to have good relationships with their fathers. Similarly, children who stayed overnight at their fathers place were considerably more likely to have good relationships than those who did not (Smith, 2004: 33). Apart from the impact on father-child relations, restrictive access militates against potential for the child to develop meaningful relations with other extended family members on the non-resident father's side. Several respondents felt that this was inherently unnatural and put additional strain on all concerned.

Extended family networks may play a role in either helping or hindering a father in gaining access to his children. For younger fathers, the attitude of the maternal grandparents was often crucial in determining whether or not they would sustain the relationship with the mother of the child, whether or not they would get access to the child and the nature of such access. Many fathers expressed regret that paternal grandparents often lost out in developing and sustaining relationships with their grandchildren. Interestingly, among the younger, marginalised fathers, paternal grandparents were likely to play at least as active a role in the lives of their grandchildren whether in the context of providing or denying support

Access to children is generally granted on the basis that the father takes all of the children together for the allotted time period. This presents serious difficulties when there are significant age gaps between children, and when they are at different stages developmentally. Similarly, it has the effect of treating the children as a collectivity when in fact they are individuals and may require varying levels of care and attention. In a number of cases, fathers found that while they could recognise that their teenage child required more one to one attention, this proved impossible because they had to take care of the younger children at the same time:

'It is impossible to cater for all three. I remember one time when we were going to the Rug Rats movie and my older son just didn't want to go. $\mathrm{He}$ didn't want to be seen going to a Rug Rats movie. And he belted his younger brother. He just lost the head. If I was a 14 year-old I would have done the same thing. What he needed and couldn't get was time with me on his own.' (Separated father, fathers' advocacy group)

Many of the non-resident fathers did not have an adequate home of their own. In terms of housing need, they were assessed as single individuals after marital breakdown which gave them low priority on waiting lists for social housing. No provision is made for a father who has overnight access to his children with the result that few fathers have the necessary facilities to make such an overnight stay possible. If you do not have an adequate home into which you can bring your children, access time with children must often be spent in public places, as one father explained: 
'I didn't have a house of my own and we didn't have anywhere to go. Every Saturday we did the North side tour (Easons, the furniture division of Arnotts, and the ILAC centre) or the South side tour (Waterstones, Stephen's Green, the shopping centre, Powerscourt, Walton's music shop. and then we had our going out Saturdays, to Dun Laoghaire on the South side or to Malahide on the North side, or the Liffey Valley Centre or Blanchardstown. Lots of days I used to say this can't go on. Either I am going to crack up or they are going to crack up.' (Separated father, fathers' advocacy group)

The Men's Centre in a North Dublin suburb recognises the need for non-resident fathers who had access to their children to have somewhere to go and accordingly provide a room equipped with cooking facilities so that the father can cook a meal for his children. This offers an alternative to the 'McDonalds Dad' syndrome which many of the participants saw as the outcome of limited access hours, lack of private transport and no place of their own to which to go.

Gaining access to the children also presented further problems for many fathers. They felt that they had to engage in constant self-monitoring when the children were in their care so that they would not leave themselves open to accusations of mistreatment or neglect. They were also highly conscious that if they did not observe the access agreement to the letter they might end up in court. These created further pressures on fathers:

'I am terrified that my kids (aged sixteen months) will fall and bang themselves and if they get a bruise. ... Toddlers fall all the time, my sister has kids who are black and blue. But I have to go around trying to protect them ... when I go up to their grandparents house I put foam on the stairs, cushions here, rubber there. You spend your whole day with your heart in your mouth. Although you only have them for a couple of days, you'd kind of go, Thank God, I got them back without a scratch or a bang.' (Father, fathers' advocacy group)

Watching the clock also became part of the new rhythm of life:

'I am always aware of time, your whole life it becomes a series of appointments. Other people can be with their children ... they have a sense that I can be with my kids ... when I want and when I don't have to be when I don't want ... this wonderful flexibility is what I have lost. I have to fit everything into these two nights ... I have to live this whole life of fitting everything into times and watching the clock. When I have to be back by 5:00 p.m., watching for the traffic, worrying about what if I am late. I just live looking at clocks now.' (Father, fathers' advocacy group) 
Gaining access to children after relationship breakdown may be difficult, but even when access is secured, fathers felt that their parenting was constantly on trial, and hence they could not let their guard down. The self-monitoring in which they engaged meant that they could never relax and be a 'good enough' father. If anything happened to the children on their watch, their access could be in jeopardy. This fear overshadowed their lives.

\section{Fatherhood denied}

Re-thinking their role as fathers, adjusting to and grieving for the absence of their children in their daily lives and adjusting to the immediacy of children needs in concentrated bursts over weekend visits were all identified as key challenges in a British study of non-resident fathers (Bradshaw et al., 1999: 122). The testimonies of the fathers who participated in the current study support the findings of the British study. Furthermore, fathers very often found that while the mother of the child received sympathy and support from friends and families, they often felt alone and isolated. There is a presumption of guilt on the part of the man if and when the relationship breaks down and he leaves the family home. Some men reported that they felt strongly the stigma of being a separated man in Irish society. In the aftermath of marital or relationship break-up many men found they had been re-labelled: from a co-parent, involved with their children to a detached visitor in their child's life to the more negative 'deadbeat dad', 'feckless father'. These stereotypes they believed were strongly dependent on the structural constraints imposed by a system that, they argued, acknowledges and promotes the rights of the mother over the father. There was a general inability to recognise much less address the pain they were feeling. This was referred to several times as an 'invisible pain':

'I was in bits. I mean it was like as if you know I was in a dream ... but you know at the beginning, I don't know about the other lads but, I felt an utter failure. You know, I'd failed my children, I'd failed her, I'd failed myself, I'd failed my parents, you know. I was utsterly isolated ... I found that I didn't have the vocabulary to talk about what I was feeling. I wasn't even aware of what my feelings were.' (Father, fathers' support group)

Most of the respondents had found solace in sharing their experiences with each other in the context of men's networks or support groups. Even among those young men from disadvantaged backgrounds who were not affiliated to any group, it was clear that the support of friends was crucial to their internalisation of the father role. Members of fathers' advocacy groups argued that socialisation processes work against the interests of men in that men are discouraged from expressing their feelings. This is exacerbated after family or relationship breakup, because men tend to lose the status of parenting which is the one arena in which they can legitimately give expression to emotion. 
The state (in terms of the judicial and social welfare system) is perceived as encouraging fathers to get out of the picture. Friends, solicitors, even family members frequently advised fathers to walk away, telling them that pursuing their rights would be too traumatic, time consuming, and costly. Men were advised to 'wait until the child is older and comes looking for you'. Respondents suggested that there is a too easy acceptance of the cultural assumption that as long as a child has a loving and caring mother there is no need to support or encourage active parenting by the father. Activist fathers in particular, sought to challenge the stereotype of fathers as people 'who walk away'.

Ironically, many of the young fathers traced their own problems to the poor role models set by their own fathers, who had themselves 'walked away'. They felt they had been neglected by them due to their absence through marital breakdown or imprisonment:

'I know what its like to lose out on a father. My father was in prison. He was in when my nanny and my granny died. He regretted that he didn't see me growing up.' (Young father, North Dublin)

Research suggests that the loss of a positive male role model can negatively impact on young boys behaviour, while the presence of a father or another positive male influence decreases the risks of behaviour problems (Florsheim et al., 1998). The young men in this study spoke of the lack of emotional care that, they felt, had damaged them in their own lives. As a result, they expressed determination to 'be there' for their children and to provide their children with the love that they may have missed out on. Fatherhood for them meant love that could be expressed in simple ways such as buying clothes or toys for their children. They felt strongly that their children should not make the same mistakes that they did, in the sense of leaving school early, engaging in criminal activity, and dabbling in drugs. They believed that they had learned about life the hard way and so were well placed to offer guidance to their own children. Many poor, unwed fathers place considerable value on the importance of biological parenthood (see Garfinkel et al., 1998). For the disadvantaged young men in this study this was the one thing that nobody could ever take away from them:

'The best thing is knowing that he is a little young fella, a little me, "a spit out of my mouth". He's mine, and no one else's. No one can take that away from you.' (Young father, North Dublin)

Activist fathers, tended to be older and therefore their children were also older. They placed much greater emphasis on developing meaningful, and mutually gratifying relationships with their children. This they saw as only achievable through a model of joint parenting. When a relationship between the former partners ends, it doesn't mean that parenting ends. Fathers also expressed concerns about 
becoming a grandfather. They worried that the their children might bring to their own relationships the legacy of their parents dysfunctional relationship, and that this legacy would in turn shape their children's relationship with their own children.

\section{Conclusion}

Kiely has argued that there is a strong and compelling argument for the continued involvement of non-resident fathers with their children (2000: 581). In particular, he suggests that policies need to be developed that offer greater support to fathers after separation, that help people to mediate an ongoing parenting role after the termination of a partner relationship and that enable non-resident fathers to maintain regular contact with their children after separation (2000: 585). In this paper I have outlined the experiences of a range of different men who have had to carve out a role as a non-resident father in the aftermath of marriage or relationship breakdown. Most found this a very challenging experience. The majority of fathers in the study, whether previously married or not, reported that they had experienced negative feeling states as a result of their current situations including susceptibility to depressive disorders, repressed feelings of anger or suicidal tendencies. Nevertheless, almost all shared a sense of commitment to their children and to embodying a fathering role, even in the face of institutional, social and economic barriers.

The routes into becoming a non-resident father are varied, and the experiences of fatherhood vary accordingly. In general, fathers who have been married and who co-parented in the early years of rearing their children were more likely than never-married fathers to commit to maintaining an active role in their children's lives over time. This is in keeping with the literature which suggests a positive link between marital status and contact levels with children among non-resident fathers (Bradshaw and Miller, 1991; Sutton, 1996). Some of the fathers who participated in the focus groups went to extraordinary lengths to maintain contact and to build meaningful relationships. But in the absence of systematic longitudinal research, we have no way of knowing how successful or otherwise these attempts to maintain father-child contact are in the post relationship or post marital situation. As Bond asserts 'we need to learn more about the ways in which non-resident fathers manage to sustain meaningful relationships with their children over the period of separation and divorce' (Bond, 1998: 21).

The impact of marital breakdown, and the issues of gaining custody and access rights, had far reaching impact on the role of fatherhood. Participants described feelings of being cut adrift, disenchanted and disillusioned. In particular, many of the fathers in a post-marital situation felt they were standing on quicksand, and that their lives had become increasingly disordered and chaotic. They were frustrated that access time spent with their children did not follow the ordinary rhythms of household life or the child's life. These fathers had great difficulty in adjusting to the situation after separation, and found themselves 'at sea' without a partner 
and without access to the role they had formerly occupied within the family. The dissolution of their relationship and the challenges posed by non-resident fatherhood was extremely unsettling for them, and had destabilised their fathering role.

Previously married fathers were much more likely to be committed and activist in relation to pursuing their rights. They expressed a strong sense of grievance that arose from their perception of institutional discrimination against non-resident fathers in society. They strongly advocated greater transparency and accountability within the family courts system, including a review of the in camera rule. For them, it was important that parental responsibility should not be defined simply in monetary terms. They argued that there should be a right to a relationship with a child as well as a responsibility for supporting a child.

For young men who become fathers under much more spontaneous and contingent circumstances, there is a greater degree of variance in terms of their commitment to their child(ren). In many instances, they lack the financial and emotional resources to meaningfully participate in their children's upbringing, and the current stipulations associated with payment of the One-parent Family Payment discourage rather than encourage family unit formation in the aftermath of an unplanned pregnancy. For some of these young men, becoming a father was the one positive experience in a life blighted by poverty, family dysfunction and social exclusion. Strategies need to be developed to find a way of affirming and supporting a fathering role among these young men.

Never-married fathers, particularly from disadvantaged backgrounds, were less likely to have continuous structured involvement in their children lives than their previously married counterparts. This echoes British, American and Australian research that demonstrates that unwed fathers have significantly less ongoing influence in their child's life than previously married non-resident fathers (Bradshaw and Miller, 1991; Seltzer, 1991; Walter, 2000). Generally speaking, unwed fathers are more likely to live in areas of high unemployment, to come from families that are disadvantaged, to have low educational attainment and weak attachment to the labour market. In addition, they have been found to possess a limited sense of personal responsibility. The young men in this study engaged in unsafe unprotected sex. They had difficulty coping with their former partners after the relationship ended and resented the power which the young woman potentially wielded over them, in gaining access to their child. Fatherhood for the disadvantaged young men in this study was not about making a commitment to a partner and creating and sharing a family home. Indeed, for some their economic marginalisation effectively rendered such a model untenable. Rather, their fatherhood was expressed through occasional childcare by them or their parents, providing some financial support if possible, and buying gifts for their child.

Paradoxically, for some of the younger marginalised men, becoming a father had brought some measure of stability and order into their otherwise chaotic lives. They generally expressed some level of commitment to their child and acknowledged the positive impacts of becoming a father. As is the case for many lone 
mothers, the birth of a child gave the young men a 'reason to better themselves'. This bears out the findings of the Prince's Trust study, which indicated that almost half of young fathers in a national sample in Great Britain said that 'being a parent had given them a reason to work hard for the future' (2001: 32). The young men in the focus groups were determined to stay out of trouble and out of prison for the sake of the child. Parenthood, therefore, had made them more aware of the consequences of their actions although in the absence of support structures and interventions this awareness did not necessarily follow through in behavioural change. Hence, while they talked about loving their children and wanting to be there for them, they had difficulty respecting their children's mothers' and continued to engage in risk-taking behaviour. Supporting young fathers to develop a positive masculine role in relation to fatherhood, and to stay involved in their child's lives would potentially not only benefit the fathers themselves but also their children. Research suggests that having a close relationship with a biological father whether or not he lives in the family home, helps to reduce delinquent behaviour in teens and improve educational attainment, smoothing the transition to adulthood (Harris et al, 1998). A study carried out by Jenny Taylor, a clinical psychologist in south London, compared a group of 'good boys' who had no criminal convictions with a group of 'bad boys' at a secure unit for unmanageable adolescents. The most striking difference between the two groups was that the majority of the 'good boys' ( 80 per cent) spoke of being close to their fathers, while almost half of the 'bad boys' ( 45 per cent) said they had no one they considered a father figure. Dr Taylor concluded that a father who disapproves of crime and shows an interest in his son acts as a crucial social control, countering negative influences such as criminal peers (The Guardian, April 5, 2001: 9). A case can be made, I would argue, for the provision of much greater support to young fathers, in particular, to maintain long term relationships with their children even when no longer in a relationship with the child's mother. These are surely issues that need to be addressed more systematically by family, education and welfare policymakers in Ireland.

\section{Notes}

1 This work was carried out by the author.

2 The One-Parent Family Payment (OFP) was introduced in 1997 and is the main income support measure for one-parent families provided by the Department of Social and Family Affairs. The OFP's main objectives relate to income support where the parent does not have sufficient means - from maintenance or employment - to provide for his or her family. For more information see, the Review of One-Parent Family Payment, Dublin: Department of Social, Community and Family Affairs, 2000.

3 Fathers' 4 Justice and Families Need Fathers are two such groups that have used high profile tactics such as the invasion of the House of Commons and stunts outside the Big Brother House and Buckingham Palace to raise the level of public awareness of how fathers are often sidelined after divorce. 
4 An attempt was made to canvass the views of both fathers who are affiliated to groups whose primary purpose is to advocate the rights of fathers and fathers who are not affiliated to such groups but nevertheless are attempting to negotiate fathering roles. Details of the focus groups are as follows:

A support/advocacy group based in South Dublin — a group of fathers ranging in age from early twenties through fifties, including formerly married and never married men.

A national advocacy group based in Dublin - a group of formerly- married and never married fathers ranging in age from early twenties through early fifties.

A group of mostly formerly-married men who are connected with a sharedparenting organisation in Dublin City

A group of young men accessed through a North Dublin Youth Service- a group of never married young fathers ranging in age from 18 to 22 years.

A group of young men accessed through a North Dublin Youth Service- a group of never married young fathers ranging in age from 20-27 years.

A group of non-resident fathers contacted through youth services in South-West Dublin City.

For comparative purposes a focus group was convened with a group of young mothers (aged 16-19 years) on a Youthreach programme. In so far as possible, the group discussion focused on the young women's relationships with the fathers of their children.

5 The research did not encompass men who were unwilling to take on a fathering role in relation to their child/ children.

6 In the case of several participants, relationship break-up had been very acrimonious. In the focus groups I only heard one side of the story. Estranged partners or wives may have had very good reasons for seeking to limit the access of the father to their child(ren).

\section{References}

Bond, Meg 1998 'Advocating for children of separated parents', Children and Society, 12: $12-24$.

Bradshaw, J., and J. Millar 1999 Lone Parents in the United Kingdom, Department of Social Security Research Report No. 6. London: HMSO.

Bradshaw, J., C. Stimson, C. Skinner and J. Williams 1999 Absent Fathers? London: Routledge.

Burghes, L., L. Clarke, and N. Cronin. 1997 Fathers and Fatherhood in Britain. London: Family Policy Studies Centre.

Edin, K. and L. Lein 1997 'Work, welfare and the single mother's economic survival strategies', American Sociological Review 62 (2): 253-66.

Florsheim, P., P. Tolan and D. Gorman Smith 1998 'Family relationships, parenting practice, the availability of male family members, behaviour of inner city boys in singlemother and two-parent families', Child Development 69: 1437-47.

Furstenberg, F., K.Sherwood, and M.Sullivan 1992 Caring and Paying: what fathers and mothers say about child support. New York: Manpower Demonstration Research Corporation.

Garfinkel, I., S. S. McLanahan and T. L. Hanson 1998 A patchwork portrait of nonresident fathers. Princeton, NJ: Center for research on child wellbeing, Princeton University, Working Paper No. 98/25 
Harris, K., F. Furstenberg and J. Marner Jr. 1998 ' Paternal involvement with adolescents in intact families: the influence of fathers over the life course', Demography 35 (2): 201-16.

Hall, Sarah 2001 'Crime linked to absent fathers', The Guardian, April 5.

Holland, Janet 1998 The Male in the Head: Young People, Heterosexuality and Power. London: Tufnell.

Huang, C-C. and W-J. Han 2004 'Perceptions of child support and sexual activity of adolescent males', Journal of Adolescence 27: 731-48.

Kiely, Gabriel 1995 'Fathers in Families', pp. 147-58 in Imelda McCarthy (ed.), Irish Family Studies. Dublin: Family Studies Centre, University College Dublin.

Kiely, Gabriel 1998 'Caregiving within Families', pp. 91-100 in K. Matthijs (ed.), The Family: Contemporary Perspectives and challenges. Leuven: Leuven University Press.

Kiely, Gabriel 2000 'Fathers as parents after separation', pp. 579-86 in B. Jans et al. (eds) Familienwissenschaftliche und Familien politische. Bonn: n.p.

McKeown, K. 2000 'Families and single fathers in Ireland.' Paper presented at Cherish Conference on the theme of The Changing Family in the New Millennium, Conrad Hotel, Dublin, 4 May.

McKeown, K., H. Ferguson and D. Rooney 1998 Changing Fathers? Fatherhood and family life in modern Ireland. Cork: Cork University Press.

Murphy-Lawless, Jo, Laury Oaks and Clare Brady 2004 Understanding how sexually active women think about fertility, sex and motherhood. Dublin: Crisis Pregnancy Agency Report No. 6.

National Economic and Social Forum 2001 Lone Parents Forum Report No. 20. Dublin: NESF.

O'Toole, Ronnie. 2004 'Time to change a policy that perpetuates poverty', The Irish Times, 25 and 27 December.

Palkovitz, R., M.A. Copes and T.N. Woolfolk 2001 “"It's like you discover a new sense of being" - Involving fathering as an evoker of adult development', Men and Masculinities 4 (1): 49-69.

Quill, Sinead 2000 Lone Fathers in Ireland: a descriptive study. Unpublished thesis submitted in partial fulfilment of the M.Sc. in Applied Social Research, Trinity College Dublin.

Seltzer, J. 1991 'Relationships between fathers and children who live apart: the father's role after separation', Journal of Marriage and the Family 53: 79-101.

Rundle, Kay, Leigh, Collette, McGee, Hannah and Richard Layte 2004 Irish Contraception and Crisis Pregnancy [ICCP] study: A survey of the general population, Report No. 7. Dublin: Crisis Pregnancy Agency.

Russell, H and M.P. Corcoran 2000 'The experience of those claiming the one-parent family payment: a qualitative study, Appendix X: Review of the One-parent Family Payment'. Dublin: Department of Social, Community and Family Affairs.

Smith, M. 2004 'Relationships of children in stepfamilies with their non-resident fathers', Family Matters (Australian Institute of Family Studies) 67: 28-35.

Speak, S., S Cameron and R. Gilroy 1997 Young single fathers: participation in fatherhoodbarriers and bridges. London: Family Policy Studies Centre.

The Prince's Trust 2001 The views and hopes of disadvantaged young people: It's like that. London: The Prince's Trust.

Walter, Maggie 2000 'Parental involvement of unwed non-resident fathers', Family Matters (Australian Institute of Family Studies) 57. 